\title{
Juan Godoy
}

\section{Ideas para una comprensión estética de Mariano Latorre}

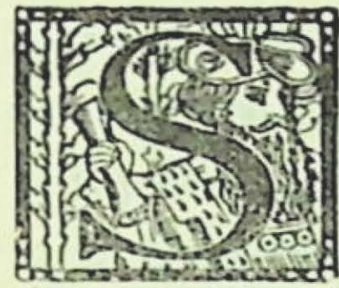

US ojos eran azules hojitas de álamo pestañeantes, abejas de luz que deponían la miel de todo el paisaje de nuestra tierra. Penetración visual y auditiva. Sus libros van da porción de la tierra chilena debe algo a Mariano Latorre.

Si Mariano Latorre hubiese sido un amante de las esencias, acaso de él tendríamos un libro - que tanto nos hace falta- sobre nuestro ser nacional. Pero tuvo un gesto de desprecio por el hombre de ideas generales y por aquel preocupado de los íntimos problemas del ser:

"En una poza que cada día tiene menos agua, filosofa un coipo sobre su próximo fin".

Su literatura muestra personajes en lucha con el medio o con los otros hombres. Recientemente del hombre consigo mismo. Todos ellos nadan en sus instintos. Sólo en un cuento suyo -en el cual no se ha reparado- cabalga un chileno consciente de sí mismo y de su pueblo: On Mardones, "de la Cordillera es Sagrada". Este cuento señala el fin de un Chile que se empinaba a la conciencia de su personalidad y su fracaso por la incomprensión de la plutocracia manida y gobernante.

Latorre cra un. puro sensorio intuitivo. 
- ¡Miren! -dijo una vez- deteniéndonos el paso a Toro Ramallo y a mí- ¡Si éste es un cielo de Blest Gana! Y un cielo húmedo, con jirones de azul entre nubes negras, con torbellino de hojas cobrizas, encarrujadas, sacudía a Santiago.

Latorre empezó escribiendo poemas líricos en prosa sobre nuestro paisaje. Luego son los animales y los niños quienes se le entregan. Era un admirable pintor de animales y niños. Ahí están los relatos "Vaca indiana", "Pichuca", "La tragedia de Moñi", "Cabinza", etc. Podría hacerse toda una galería de niños sacados de obras de Latorre. Por fin, "con regusto a mosto recién restregado", saboreó el ánima del hombre. Y en él "Domingo Persona", el mejor relato de su obra maestra Hombres y zorros. $\mathrm{Y}$ uno de los mejores que se hayan escrito en toda la América española, brota el alma del huaso en toda su desnudez.

Nuestra literatura $-\mathrm{y}$ la literatura toda de Hispanoamérica discierne dos corrientes bien diseñadas. Una, la de aquellos disidentes de ojos abismados por las cosas de Europa y con marcado complejo de inferioridad racial, que hacen literatura vaporosa, deshuesada y castrada, que podría firmar cualquier escritor europeo de último orden, y otra, aquella que busca corazón y forma iberoamericanos. Los disidentes nos parecen hijos de rastacueros, buscando espaldarazos. Un puro síntoma de la inseguridad hispanoamericana. Con estética delante, que pende como soga para sus cuellos.

En lo económico, nuestra plutocracia está con los imperialistas. En literatura, unos pobres hombres han vendido sus almas a los imperialismos literarios.

Latorre, en cambio, aunque acarreaba todas las técnicas -su biblioteca, como se sabe, poseía una sección de novelas completísima y universal - procedía con el noble afán de penetrar la materia poética que plasmaba, por el gran amor de su tierra.

En sus primeras obras se yergue Latorre con una técnica perediana. Luego es el Blasco colorista, pintoresco y regional. Se endereza hacia los franceses Maupassant, Daudet, etc. (Zola influye en su obra a través de Blasco). Su otra manera, su preocupación por el hombre, 
por el espíritu del hombre, que aparece muy definida en su libro Chilenos del mar - que marca un hito muy importante en su producción literaria - moviliza la técnica de los sajones y Conrad, principalmente. Sus dos libros On Panta y Hombres y zorros, lo muestran un lawrenciano larvado y un surrealista, con magníficos toques de O'Neill.

Su obra Hombres y zorros, que se abre para el ojo inexperto como un conjunto de relatos inconexos sobre la Cordillera de la Costa, es justamente una novela en el más estricto y moderno sentido. Bajo la aparente disparidad de los relatos corre la clara vertiente de su unidad interior. Latorre logró, con inusitado vigor, crear una atmósfera artística que penetra, envuelve y empapa de realidad: su Chillehue. Fusión y compenetración. Paisajes, animales, hombres, en relaciones simétricas y función del espíritu. Los cerros son calvos zorros de un gris rojizo, atardeciendo. Y la borrachera de los pipeños vinos alborozados identifica al hombre y al zorro. Libro surrealista y al modo de espíritu de John Dos Passos.

Latorre ha hecho bien. La técnica europea y norteamericana armó su espíritu tan nuestro, para deponer substancia artística chilena con los jugos de nuestra realidad.

Basta de concepciones tradicionalistas de la novela. De exposición, nudo y desenlace. Con un personaje de cabo a rabo. Eso queda para aquellos escritores difuntos en vida, misoneístas de gafas, de espíritus comidos de calvicie. Y chambergo. La realidad es otra. Una interferencia de planos. Una perspectiva cambiante. Nunca un solo punto de vista.

A través de lo dicho para una comprensión de Latorre, se ve, pues, su desplazamiento continuo desde el paisaje, animales y niños "fragmentos del paisaje", hacia el hombre. Y su técnica cada vez renovada. De ahí que cada nuevo libro suyo haya sido una renovación suya. De espectador ha pasado a ser un hombre que vive dentro de sus creaciones. Su libro Hombres y zorros es acabada síntesis de contenido y procedimientos: El hombre y su paisaje.

Espíritu rico de innumerables vetas, Latorre es un lírico notable (estaría bien reunir en un volumen sus admirables poemas en 
prosa). $Y$ un gran estilista. Emerge en algunos relatos su vena humorística que conduce también a la áurea poza de su alma.

Veamos ahora algunos de sus últimos cuentos:

"El piñón" nos le muestra en su escritorio, sorprendido por el crepitar de una cabeza de araucaria, que ha traído de sus andanzas por la zona austral y que deja olvidada en un anaquel. De pronto, madura, estalla la piña en una lluvia de piñones que le evoca toda la selva de nuestro prodigioso sur.

"El caracol", tan fino de estilo, son páginas de infancia y reminiscencias junto a su madre en Valparaíso. Siempre fué Latorre celador de su intimidad más profunda; pero dase ahora a contar de sí. Y nos parece tan auténtico.

El último cuento que me leyó dejóme una impresión de belleza inolvidable: La visión voluptuosa de un mozo profesor en una playa chilota, de encoger, estremecida, una muchacha, una de las plantas de sus pies en la arena...

En estos cuentos culmina su obra; culmina el desplazamiento desde el paisaje, animales y niños hacia el hombre.

Latorre nos dió un instrumento literario. El era esencialmente un hombre de letras. No vió o apenas rozó la explotación del terrícola por los grandes latifundios o la de los mineros en los yacimientos de cobre o de carbón.

Una tarde le vi dormir, sentado en un sillón, junto a la chimenea, y presentí su muerte. 


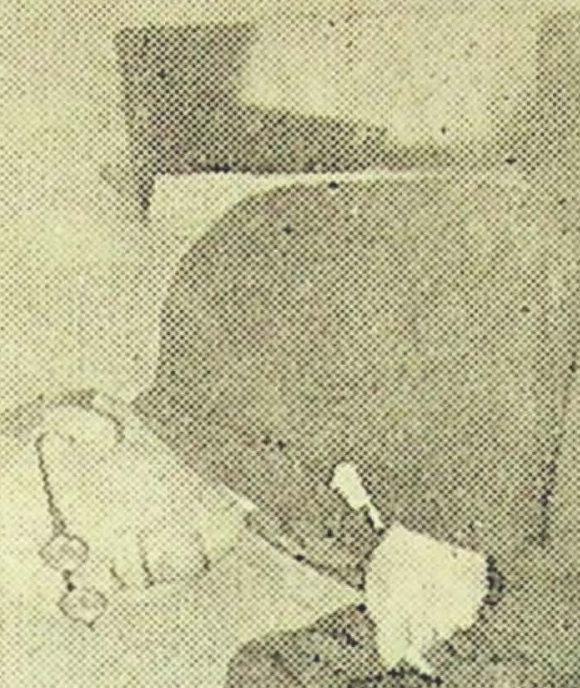

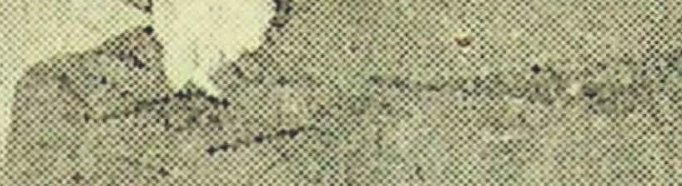
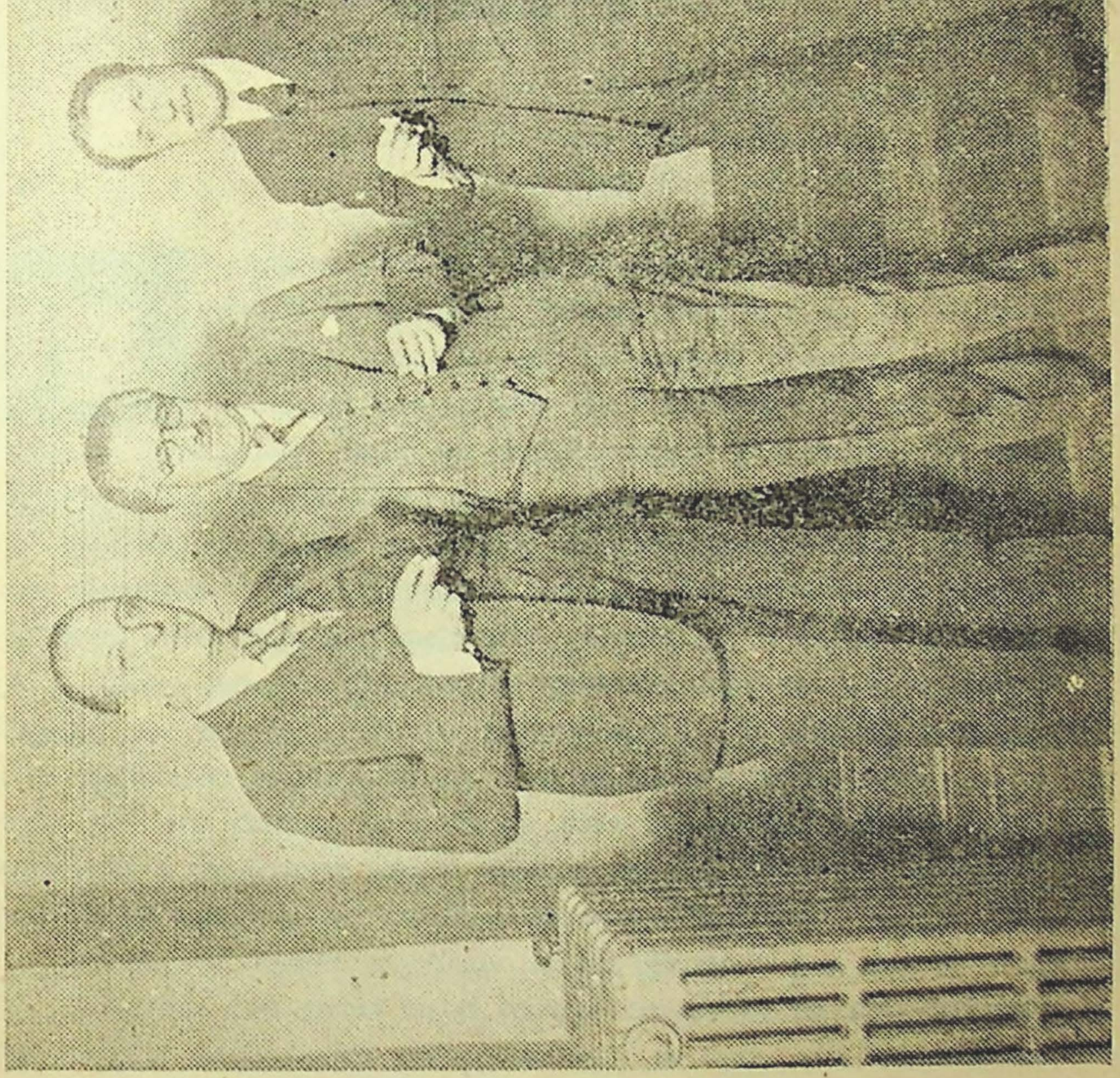

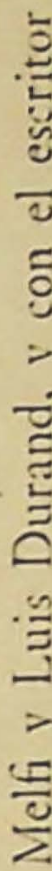

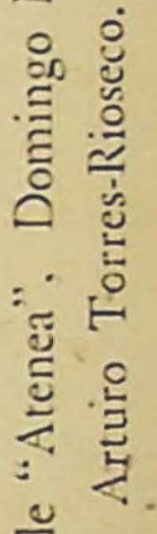

는

-

ex

อิ

อิ

点.

ঙํํำ

올 